\title{
PREVALENCE AND FACTORS ASSOCIATED WITH MALARIA TREATMENT AMONG PREGNANT WOMEN IN SELECTED RURAL AND URBAN HEALTH CENTRES IN OSUN STATE
}

\author{
Sule Joy Eghonghon, Professor Dora Akinboye, Olabode A.T. and James Uduakabasi
}

Department of Public Health, Babcock University, Ilishan -Remo, Ogun State, Nigeria

Cite this article:

Sule J.E., Dora A., Olabode

A.T., James U. (2021),

Prevalence and Factors

Associated with Malaria

Treatment Among Pregnant

Women in Selected Rural and

Urban Health Centres in Osun

State. African Journal of

Health, Nursing and

Midwifery 4(3), 92-104. DOI:

10.52589/AJHNM-

PEXKRS59.

\section{Manuscript History}

Received: 10 May 2021

Accepted: 31 May 2021

Published: 12 June 2021

Copyright $\odot 2020$ The Author(s). This is an Open Access article distributed under the terms of Creative Commons Attribution-NonCommercialNoDerivatives 4.0 International (CC BY-NC-ND 4.0), which permits anyone to share, use, reproduce and redistribute in any medium, provided the original author and source are credited.
ABSTRACT: Background: Malaria is one of the killer diseases worldwide majorly transmitted by the bite of infected female Anopheles mosquitoes. Malaria during pregnancy remains a major public health concern in many sub-Saharan African countries with Nigeria having the highest prevalence rate (27\%). Purpose: This study was therefore designed to assess the prevalence and factors associated with treatment of malaria among pregnant women in selected rural and urban health centres in Osun State, Nigeria. Materials and Methods: Two hundred consenting pregnant women were selected using a multi-stage sampling technique from eight PHCs from Olorunda and Osogbo LGAs. The study was a facility-based, cross-sectional comparative survey using semi-structured interviewer-administered questionnaires Descriptive statistics, Chi-square tests and logistic regression were used to analyze data and the level of statistical significance was set at $\alpha \leq 0.05$. Results: Mean age of $28.29 \pm 7.23$ and $28.37 \pm 6.90$ for rural and urban PHCs respectively. All the respondents are Yoruba, almost two-thirds and more than half were Muslims and Christian in rural and urban LGAs respectively. The sero-prevalence of malaria was higher among women in urban PHCs (11\%) compare to women in rural PHCs (4\%) with cumulative sero-prevalence of $7.5 \%$ for both LGAs, the healthseeking for women in rural area is better compare to those women in urban area. Conclusion: This study provides a better understanding of malaria in pregnancy in the study areas with a clear contrast on prevalence, health-seeking behaviour and treatment practice between the target groups two LGAs.

KEYWORDS: Malaria Treatment, Pregnant Women, Health Centres, Osun State Nigeria 


\section{INTRODUCTION}

Malaria is a parasitic disease of tropical origin that is caused by five species ( $P$. falciparum, $P$. malaria, $P$. ovale, $P$. vivax, and $P$. knowlesi) of the genus protozoa and transmitted by the bite of infected female Anopheles mosquitoes (Fana, Bunza, Anka et al., 2015). In malaria endemic areas, pregnant women are the highest group for malaria infection and to develop a severe form of the disease that could result in mortality.

It has been reported that in sub-Saharan Africa, malaria can cause as many as 10,000 cases of malaria-related deaths in pregnancy per year (WHO, 2020). Nigeria contributes to $27 \%$ of all cases globally, which makes it the highest contributor of all the countries. The number of deaths of malaria has gradually reduced from 736,000 to 409,000 in 2019, with African region accounting for the highest number of deaths. under 5 children are the most vulnerable victims of malaria, yet to develop immunity against malaria accounting for $67 \%$ of the deaths globally.

Pregnant women with malaria have an increased risk of abortion, stillbirth, premature delivery and low-birthweight infants which may be due to combination of stresses which, on one hand, is directed at ensuring the survival of the fetus and, on the other, at combating the parasite (Saba, Sultana and Mahsud, 2008).

Therefore, the most substantive malaria prevention and control measures as recommended by World Health Organization (WHO, 2004) include a three-pronged strategy for control of malaria in pregnancy in Africa including case management (prompt treatment with highly effective drug), use of insecticide-treated nets (ITNs) and intermittent preventive treatment (IPTp), the administration of a full treatment course of an effective antimalarial at regular antenatal visits, usually a month apart (Rogerson, 2017).

\section{METHODOLOGY}

\section{Study Population}

The study was carried out in one rural and urban Local Government Areas in Osogbo, Osun State, Nigeria. Osogbo is the state capital of Osun state with a landed area of about 835 hectare and population projection of over 3 Million people as at 2006 population census. The climate in Osogbo is tropical with two seasons; October to February (dry season) and March to July rainy season. The average daily temperature is $32^{\circ} \mathrm{C}$ with a minimum temperature of $19^{\circ} \mathrm{C}$ and a maximum temperature of $35.9^{\circ} \mathrm{C} 14$. Malaria transmission is usually intense in the rainy season in the study areas. The study population were pregnant women residing within Osogbo and Olorunda Local Government Areas. Osogbo (Urban) and Olorunda (Rural) are two of the largest urban and rural local governments in the state with the highest population.

\section{Inclusion Criteria}

All pregnant women residing within Osogbo and Olorunda LGAs that are attending PHCs within the LGAs for their ANC services and gave consent to participate were included in the study. 


\section{Exclusion criteria}

All pregnant women who met the inclusion criteria but that had any pregnancy related complications like eclampsia; high blood pressure etc. were excluded from this study.

\section{Sample Size determination}

Sample size for this study was estimated using the Leslie Kish formula for single proportion which is as follows:

\section{$\underline{\mathrm{N}=\mathrm{Z}^{2} \mathrm{pq}}$}

$$
d^{2}
$$

$\mathrm{N}=$ Minimum sample size

$\mathrm{Z}=$ Standard normal deviation set at 1.96 normal interval

$\mathrm{p}=$ Estimate of prevalence of malaria in pregnancy.

The minimum sample size was determined using prevalence derived from a study (Seroprevalence of malaria, hepatitis $b$ and syphilis among pregnant women in Osogbo, Southwestern Nigeria by Adeleke et al., 2013) which was $13 \%$

$\mathrm{q}=$ Proportions that does not have the characteristics being investigated

$$
(q=1-p) \quad q=1-0.13=0.87
$$

$\mathrm{d}=$ Degree of accuracy set at 0.05 (precision set at $5 \%$ significant)

Therefore, the sample size $\mathrm{N}=\underline{(1.96)^{2} \times 0.13 \times 0.87}$

$$
0.052
$$

$$
\begin{aligned}
& \mathrm{N}=\underline{0.435}=173.7 \sim 174 \\
& 0.0025
\end{aligned}
$$

A non-response rate of $10 \%$ of $174=174 \times 10 \%=17.4 \sim 17$

Therefore, 17 will be added to the sample size calculated (174) to make the sample size 191 in order to address issues of incomplete response $(174+17=191)$

$\mathrm{N}=191$

The total sample size $=191$

However, the researcher decided to approximate the total sample to 200 hundred in order to improve the statistical power and to be able to divide the respondents among the PHCs equally.

\section{Sampling procedure}

A multi stage sampling procedure was used to select 200 pregnant women among all the women attending ANC services at PHCs in the study areas. 
The first step was to randomly select four public urban and rural PHCs from the two LGAs (Urban PHC selected in Oshogbo LGA are Oke-Oluwatosin PHC, Ago-Ayo PHC, Ayepe PHC and Oke Baale PHC; while the rural PHCs selected from Olorunda LGAs are Atelewo PHC, Ota-Efun PHC, Enikan-Oyun PHC and Biiro Fagbemi PHC) (Nigeria Health Facility Registry (HFR), Federal Ministry of Health, 2019).

The second stage was to split the number of intending respondents by the number of selected PHCs $(200 \div 2=100)$

The third stage involved allocation of 100 respondents to all the four PHC, with each PHC getting 25 allocation samples of respondents

The fourth stage was the selection of the respondents by simple random sampling in PHCs with more than 25 respondents (For example Atelewo, Ota Efun, and Enikan-Oyun).

\section{Data Collection Method}

Rapid diagnostic Test (RDT) was used to measure the prevalence of the malaria parasite among the respondents and this was specifically done by the Healthcare workers at those PHCs. The procedure involved taking a blood sample from the thumb of the respondents. The respondents fourth finger's were disinfected and allowed to air dry; the fingers were pricked, with the first blood wiped off the finger with cotton wool, then the inverted cup or capillary was used to draw whole blood specimens. The blood was transferred into the marked cassette with the ID of the respondent. The results was then read and recorded within a minimum of 15 minutes and maximum of 30min (per kit's manufacturer's instructions)

The quantitative method was used for the other part of the data collection; Primary data was collected in this study through the use of semi-structured interviewer-administered questionnaires. The questionnaire was measured using a 30-point scale; scores between $\leq 15$, and $>15 \leq 30$ were categorized as negative health-seeking behaviour and positive health-seeking behaviour respectively, while similar scaling was used for other sections including the practice and factors influencing malaria treatment. The questionnaire was structured based on the information obtained from literature on their health-seeking behaviours, level of practice of malaria treatment, factors responsible for their practice in addition to the socio-demographic characteristics of the respondents.

The questionnaire was divided into four sections which are:

- Section A: Socio-demographic characteristics of respondents

- $\quad$ Section B: Health-seeking behaviors related to malaria treatment among respondents

- $\quad$ Section C: Practice of malaria treatment among respondents

- Section D: Factors associated with practice of malaria treatment among respondents

\section{Instrument}

There was an extensive review of literature to ensure appropriate content and face validity. Construct validity was also ensured by making sure that variables in the theoretical framework are well represented in the instrument. The instrument was also given to my supervisor as well 
as some research experts in the Faculty of Public Health Babcock University to help ascertain the quality of the instrument. The instrument was also translated to Yoruba Language and was translated back to English to ensure that it retained its original meaning. The drafted questionnaire was field tested among $10 \%$ of the sample size, which was (20 for Urban LGA and 20 for Rural LGA) among similar respondents in Abere Health Clinic in Ede North LGA (urban) and Ibokun PHC in Obokun LGA (rural) which both has a similar socio-demographic characteristic with the study site. The retrieved field-tested questionnaire was however subjected to Cronbach alpha analysis and a reliability coefficient of 0.81 was recorded which is more than 0.7 that was initially predicted.

\section{Data Management and Analysis}

Copies of the questionnaire collected were checked for completeness and accuracy. They were cleaned, sorted, coded using a developed coding guide. Data was processed and analysed using Statistical Packages SPSS version 25. Descriptive and Inferential statistics were used to present the data with frequency table, mean with standard deviation, chi square; student t-test to compare prevalence between the two LGA and Study settings and logistic regression to do a predictive description of the data.

\section{Ethical Consideration}

Ethical approval was obtained from the Babcock University Health Research Ethics Committee and Osun State Health Research Ethics Committee at the Primary Healthcare Centre Management Board at Kelebe Osogbo prior to the commencement of the study due to the level of the evasiveness of the study that requires drawing of blood samples by the Healthcare workers. Verbal informed consent was obtained from participants after providing them with information and benefits of the research. With collaboration with their regular healthcare providers, the respondent was also assured that the blood obtained was only for RDT as they were also there when the test was conducted. that the information provided by them will be kept confidential so as for them to be sincere with the responses they provided. They were also informed that they are free to withdraw from the research if need arises.

\section{RESULT}

This presents the findings of the study which assessed the prevalence and factors associated with malaria treatment among pregnant women in selected rural and urban health centres in Osun state. Two hundred pregnant women between the ages of 15 to 45 were interviewed at eight Primary Healthcare Centres (PHCs) at two different Local Government Areas (Urban and Rural LGAs) in Osun state. The study employs a clustered sampling method to select four PHCs each from Osogbo LGA and Olorunda LGA respectively, where the former an urban LGA and the latter a rural LGA. The PHCs selected from the urban LGA are: Oke-Baale PHC, Ago-Ayo PHC, Oke Oluwatosin PHC and Ayepe PHC while the PHCs selected from the rural LGA are: Atelewo PHC, Ota-Efun PHC, Enikan-Oyun PHC and Biiro-Fagbemi PHC. This study assessed an equal number of respondents from each PHC (25 pregnant women/ 25 questionnaires were administered to the participants at eight PHCs $(25 \times 8=200)$ making a total of 200 questionnaires that were administered in this study). 


\section{The Socio-demographic Characteristics of the Respondents}

It was observed that the age group 25-39 years had the highest participants in both the rural PHCs and urban PHCs, $58(58 \%)$ and $61(61 \%)$. Most of the participant in the rural PHCs practiced Islam, $62(62 \%)$ while most of the participants in the urban PHCs practiced Christianity $55(55 \%)$. Most of the participants in the rural PHCs had secondary education $(56 \%)$ while tertiary education was the highest in the urban PHCs (46\%). Tertiary education was recorded to be the highest form of education of the husbands of the participants, $55 \%$ in rural and 66\% in urban PHCs. Trading/Business was the highest occupation at both PHCs, 40\% in rural and $32 \%$ in urban PHCs. Most participants in the rural PHCs were in their $3^{\text {rd }}$ trimester $(39 \%)$ while most of the participants in the urban PHCs were in their $2^{\text {nd }}$ trimester $(35 \%)$. Polygamy was the highest type of marriage in both PHCs. Most of the participants had one child, rural (20\%) and urban (30).

Most of the participants resided in flat apartments, $49 \%$ in the rural PHCs while most of the participants in the urban PHCs resided in bungalow apartments (53\%). Most of the participants $(62 \%)$ in the rural PHCs did not disclose their average income, however (9\%) each earn between 1-9999, 10000-19999 and 30000-39999, however, most of the participants (20\%) in the urban PHCs earned between 1-9999. A larger percentage (75\%) of the urban PHCs do not have a family doctor, while $44 \%$ were reported to have a family doctor.

Table 4.1 Socio demographic characteristics of the participants

\begin{tabular}{lll}
\hline Variables & Rural, $\mathbf{N}=\mathbf{1 0 0}(\%)$ & Urban, $\mathbf{N}=\mathbf{1 0 0}(\mathbf{\%})$ \\
\hline Age group & & \\
15-24 years & $36(36)$ & $34(34)$ \\
25-39 years & $58(58)$ & $61(61)$ \\
$>40$ years & $6(6)$ & $5(5)$ \\
Religion & & \\
Islam & $62(62)$ & $40(40)$ \\
Christianity & $36(36)$ & $55(55)$ \\
Traditional & - & $3(3)$ \\
No response & $2(2)$ & $2(2)$ \\
Level of education & & \\
No Formal Education & $2(2)$ & $9(9)$ \\
Primary & $2(2)$ & $9(9)$ \\
Secondary & $56(56)$ & $36(36)$ \\
Tertiary & $35(35)$ & $46(46)$ \\
No response & $5(5)$ & - \\
Husband level of education & & \\
No Formal Education & $2(2)$ & $4(4)$ \\
Primary & - & $1(1)$ \\
Secondary & $25(25)$ & $20(20)$ \\
Vocational & $11(11)$ & $2(2)$ \\
Tertiary & $55(55)$ & $66(66)$ \\
No response & $7(7)$ & $7(7)$ \\
Occupation & & \\
Civil Servant & & $5(5)$ \\
House Wife & $4(4)$ & $5(5)$ \\
\hline
\end{tabular}


African Journal of Health, Nursing and Midwifery

ISSN: 2689-9418

Volume 4, Issue 3, 2021 (pp. 92-104)

www.abjournals.org

\begin{tabular}{|c|c|c|}
\hline Artisan & $13(13)$ & $1(1)$ \\
\hline Labourer/Cleaner & $4(4)$ & $1(1)$ \\
\hline Student & $6(6)$ & $5(5)$ \\
\hline Unemployed & $3(3)$ & $28(28)$ \\
\hline Trading/Businesswomen & $40(40)$ & $32(32)$ \\
\hline Professional & $6(6)$ & $9(9)$ \\
\hline Others () & $4(4)$ & $13(13)$ \\
\hline No response & $6(6)$ & $1(1)$ \\
\hline \multicolumn{3}{|l|}{ how long have you been married } \\
\hline $0-2$ & $37(37)$ & $48(48)$ \\
\hline $3-5$ & 19 (19) & $27(27)$ \\
\hline $6-8$ & $14(14)$ & $7(7)$ \\
\hline $9-11$ & $8(8)$ & $3(3)$ \\
\hline$>11$ years & $9(9)$ & - \\
\hline \multicolumn{3}{|l|}{ what is the stage of your pregnancy } \\
\hline 1st Trimester & $13(13)$ & $19(19)$ \\
\hline 2nd Trimester & $11(11)$ & $43(43)$ \\
\hline 3rd Trimester & $39(39)$ & $35(35)$ \\
\hline I don’t know & $37(37)$ & $3(3)$ \\
\hline Variables & Rural, N = $100(\%)$ & Urban, $N=100(\%)$ \\
\hline What is your type of marriage? & $32(32)$ & $10(10)$ \\
\hline \multicolumn{3}{|l|}{ Polygyny } \\
\hline Monogamy & $48(48)$ & $80(80)$ \\
\hline No response & $20(20)$ & $10(10)$ \\
\hline \multicolumn{3}{|l|}{ how many children do you have } \\
\hline 1 & $20(20)$ & $30(30)$ \\
\hline 2 & $23(23)$ & $12(12)$ \\
\hline 3 & $12(12)$ & $3(3)$ \\
\hline 4 & $2(2)$ & - \\
\hline \multicolumn{3}{|l|}{ what type of house do you live } \\
\hline Bungalow & $29(29)$ & $53(53)$ \\
\hline Flat apartment & 49 (49) & $39(39)$ \\
\hline Duplex & $5(5)$ & $4(4)$ \\
\hline Other & $9(9)$ & $1(1)$ \\
\hline No response & $8(8)$ & $3(3)$ \\
\hline \multicolumn{3}{|l|}{ Average monthly income } \\
\hline $1-9999$ & $9(9)$ & $20(20)$ \\
\hline $10000-19999$ & $9(9)$ & $11(11)$ \\
\hline $20000-29999$ & $6(6)$ & $7(7)$ \\
\hline 30000-39999 & $9(9)$ & $4(4)$ \\
\hline$>50000$ & $5(5)$ & $1(1)$ \\
\hline No response & $62(62)$ & $2(2)$ \\
\hline Do you have family doctor & & \\
\hline
\end{tabular}




\begin{tabular}{lll}
\hline Yes & $44(44)$ & $23(23)$ \\
No & $47(47)$ & $75(75)$ \\
Don't know & $9(9)$ & $2(2)$ \\
\hline
\end{tabular}

\section{Sero-Prevalence of Malaria in the Study Sites}

Based on the positivity of the RDT, the cumulative prevalence of malaria among the participants was $7.5 \%$, the urban PHCs had $11(11 \%)$ positive malaria cases across their PHCs while the rural PHCs had $4(4 \%)$ positive malaria across their PHCs.

In the rural PHCs, only Atelewo and ota-efun had positive malaria cases, 3(75\%) and 1(25\%) respectively. In the urban PHCs only Oke-baale and Ago-ayo had positive malaria cases, $8(72.7 \%)$ and $3(27.3 \%)$ respectively.

Table 4.2 Sero-prevalence of malaria in the study sites

\begin{tabular}{lll}
\hline Variables & $\mathbf{N}=\mathbf{2 0 0}$ & \% \\
\hline RDT sero-positivity & 15 & 7.5 \\
Positive & 185 & 92.5 \\
Negative & & \\
Prevalence of malaria in the study sites, N & & \\
$\mathbf{1 1 5}$ & & 4.0 \\
Rural PHCs & 4 & 96.0 \\
Positive & 96 & 11.0 \\
Negative & & 89.0 \\
Urban PHCs & 11 & \\
Positive & 89 & 75.0 \\
Negative & & 25.0 \\
Rural PHCs & 3 & 0 \\
Atelewo & 1 & 0 \\
Ota-efun & 0 & \\
Enikan-oyun & 0 & 72.7 \\
Biro-fagbemi & & 27.3 \\
Urban PHCs & 8 & 0 \\
Oke bale & 3 & 0 \\
Ago-ayo & 0 & \\
Oke oluwatosin & 0 & \\
Ayepe &
\end{tabular}

\section{The Health Seeking Behaviors Related to Malaria Treatment among Respondents}

Only a few of the participants were on NHIS, eight participants in the rural PHC and nine participants in the urban PHCs. Most of the participants in this study registered for ANC at their $1^{\text {st }}$ trimester, twenty-seven participants in the rural PHCs and seventy-three in urban PHCs, there was an association of this behavior within the rural and urban participants $(\mathrm{P}=$ 0.001). Many of the participants in the rural PHCs (55) believed that every symptom related to fever is an onset of malaria participants while many of urban participants (63) did believe 
otherwise. Most of the rural participants (55) would visit any hospital as the first action if they experience any health problems, meanwhile, most of the urban participants (61) would visit any pharmacy as the first action if they experience any health problems. Most of the participants (60 rural participants and 74 urban participants) claimed that they do follow the doctor's advice in treating malaria. 37 rural participants prefer to go to PHCs for treatment while 69 urban participants would prefer to PHC for treatment.

Table 4.3. The health seeking behaviors related to malaria treatment among respondents

\begin{tabular}{|c|c|c|c|}
\hline Variables & Rural & Urban & $\begin{array}{l}\text { Chi-square } \\
\text { significance }\end{array}$ \\
\hline $\begin{array}{l}\text { Are you on NHIS, if yes mention the name of the } \\
\text { facility you registered }\end{array}$ & & & 0.983 \\
\hline Yes & 8 & 9 & \\
\hline No & 80 & 89 & \\
\hline When did you register for ANC & & & 0.001 \\
\hline First trimester & 27 & 73 & \\
\hline Second trimester & 27 & 23 & \\
\hline Third trimester & 12 & 3 & \\
\hline I did not register & 20 & 0 & \\
\hline $\begin{array}{l}\text { Do you believe that every symptoms related to } \\
\text { fever is an onset of malaria }\end{array}$ & & & 0.001 \\
\hline Yes & 55 & 36 & \\
\hline No & 34 & 63 & \\
\hline $\begin{array}{l}\text { If you are experiencing any health problems, what } \\
\text { is the first action that you will take }\end{array}$ & & & 0.001 \\
\hline Visit any Hospital & 74 & 33 & \\
\hline Visit any Pharmacy & 12 & 61 & \\
\hline Others & 0 & 4 & \\
\hline Whose advice do you follow in treating malaria & & & 0.194 \\
\hline Doctor & 60 & 74 & \\
\hline Pharmacist & 1 & 8 & \\
\hline Nurse & 1 & 2 & \\
\hline Family/friends & 4 & 9 & \\
\hline Which hospital do you prefer to go for treatment & & & 0.001 \\
\hline PHC & 37 & 69 & \\
\hline General hospital & 38 & 10 & \\
\hline Teaching/tertiary hospital & 10 & 15 & \\
\hline Others & 3 & 1 & \\
\hline
\end{tabular}




\section{The Practice of Malaria Treatment among Respondents}

For the two PHCs, there were few episodes of malaria in the past three months, rural PHCs (38) and urban PHCs (28), with significant association $(\mathrm{P}=0.05)$. In the last three months, most of the participants (63 in the rural PHCs and 24 in the urban PHCs) have been taking their medicine based on doctors' advice, with significant association $(P=0.03)$. Most of the rural participants (26) took their drug once while most of the urban participants (25) took their drug three times. Most rural participants (47) and urban participants (65) reported that they were not given drugs for malaria treatment when they did not have malaria, with significant association $(\mathrm{P}=0.003)$.

Table 4.4 The practice of malaria treatment among respondents

\begin{tabular}{llll}
\hline Variables & Rural & Urban & $\begin{array}{l}\text { Chi-square } \\
\text { significance }\end{array}$ \\
\hline In the past three months have you had any episode & & & 0.05 \\
of malaria & 38 & 28 & \\
Yes & 53 & 71 & \\
No & & & 0.03 \\
In the past three months, how did you take your & & & \\
medicines to treat malaria & 63 & 24 & \\
Based on doctors' advice & 3 & 8 & \\
Using my past experience to buy drugs for us & 0 & 2 & \\
Following Friends and Family advice & 1 & 2 & 0.001 \\
Others & & & \\
How many times did you use the drugs & 26 & 4 & \\
1.00 & 23 & 5 & \\
2.00 & 17 & 25 & \\
3.00 & 4 & 0 & \\
7.00 & & & 0.002 \\
Was it the same drug you have been using before & 25 & 5 & \\
Yes & 27 & 28 & \\
No & & & \\
Were you given drugs for malaria treatment even & & & \\
when you did not have malaria & 18 & 6 & \\
Yes & 47 & 65 & \\
No & & & \\
\hline
\end{tabular}

Factors Associated with Practice of Malaria Treatment among Respondents

The mean cost of malaria treatment was reported to be N1825 \pm 1156.1 , the minimum cost was 800 and the maximum cost was 5000 in the rural PHCs while the mean cost of treatment in the urban PHC was N1432 \pm 376.1 and minimum cost N200 and maximum cost was N2500. Some of the rural participants bought their drugs from chemists (36) while most of the urban participants (70) did not buy drugs from pharmacy and chemist. The most common anti-malaria bought from pharmacies was fansidar in the rural PHCs while Arthemeter was the most commonly used anti-malaria in the urban PHCs. Most of the rural PHCs participants (30) reported that the drug was similar to what they would get at the health center, while most of 
the urban PHCs participants (21) said the drugs were not similar to what they would get at the health center. Most of the participants at the rural PHCs (47) preferred to get treatment from health centres while just 12 participants preferred to buy from health centres. Most of the participants preferred their choices because the drugs would work effectively.

Table 4.5 Factors associated with practice of malaria treatment among respondents

\begin{tabular}{|c|c|c|}
\hline Variables & Rural PHCs & Urban PHCs \\
\hline \multicolumn{3}{|c|}{$\begin{array}{l}\text { Average cost on malaria treatment per } \\
\text { month }\end{array}$} \\
\hline Mean \pm S.D & $1825.9 \pm 1156.1$ & $1432 \pm 376.1$ \\
\hline Minimum & 800 & 200 \\
\hline Maximum & 5000 & 2500 \\
\hline \multicolumn{3}{|c|}{$\begin{array}{l}\text { Do you buy anti malaria drugs from } \\
\text { pharmacy or chemist just to save money }\end{array}$} \\
\hline Yes & 32 & 21 \\
\hline No & 36 & 70 \\
\hline \multicolumn{3}{|c|}{ What is the name of the drug } \\
\hline Mode (commonly used) & Fansidar & Arthemeter \\
\hline \multicolumn{3}{|c|}{$\begin{array}{l}\text { Is the drug the same with the one you are } \\
\text { given from the health centers }\end{array}$} \\
\hline Yes & 30 & 4 \\
\hline No & 24 & 21 \\
\hline \multicolumn{3}{|c|}{ Which one do you prefer } \\
\hline Bought & 14 & 13 \\
\hline Health Centre & 47 & 12 \\
\hline None of the two & 2 & 4 \\
\hline \multicolumn{3}{|c|}{ Reason why you prefer the one you prefer } \\
\hline Works effectively & 13 & 10 \\
\hline Doctors' prescription & 12 & 2 \\
\hline Cost effective & 4 & 0 \\
\hline Because it's free & 5 & 0 \\
\hline \multicolumn{3}{|c|}{$\begin{array}{l}\text { Do you have any significant others buy you } \\
\text { antimalarial drugs }\end{array}$} \\
\hline Husband & 11 & 34 \\
\hline Siblings & 1 & 10 \\
\hline Father & 3 & 2 \\
\hline Mother & 1 & 1 \\
\hline \multicolumn{3}{|c|}{$\begin{array}{l}\text { How often does your significant others buy } \\
\text { you antimalarial drugs }\end{array}$} \\
\hline All the time & 15 & 11 \\
\hline Once in a while & 24 & 34 \\
\hline Rarely & 4 & 10 \\
\hline Never & 19 & 4 \\
\hline
\end{tabular}




\section{DISCUSSION}

This study was set out to examine the prevalence and factors associated with treatment of malaria among pregnant women. It was found out that the cumulative prevalence of malaria at the PHCs is low. It was a study conducted among pregnant women of different levels of education, though a higher percentage of the pregnant women in the rural PHCs had secondary level of education while a number of pregnant women in the urban PHCs had tertiary education. The level of education has shown to be a great influence and association on the knowledge of respondents about malaria along with malaria control (Oladimeji et al., 2019).

The respondent age ranges between 15 to above 40 at both rural and urban LGAs with a mean age of $28.29 \pm 7.23$ and $28.37 \pm 6.90$ for rural and urban PHCs respectively. It was observed that more than half and nearly two-third of the respondents fall into the 25-39 age category probably because of the fact that the National Demographic Health Survey (NDHS) (2018) reported that the median age at first birth is between 25-49 years age in Nigeria.

The study also revealed a high preference of the anti-malaria drug among respondents who accessed rural PHCs which was as a result of the drug working effectively which was then concluded to be doctors' prescription, and cost-effectiveness and the preferred the anti-malaria drug because it was free.

The results from this study also revealed the variation in preference in where the anti-malaria drugs were obtained from, with larger number of participants from the rural PHCs preferring anti-malaria drugs administered at the health centre to that which is purchased at the pharmacy/store on the contrary to the number of participants from the urban PHCs.

In conclusion, malaria has been one of the most challenging infectious diseases to eradicate in Africa. This study showed that the cumulative prevalence of malaria at the PHCs is low. In the two LGAs, the prevalence of malaria in the rural PHCs was lower than those of Urban. The major factors that were identified with the practice of malaria treatment is the cost of monthly treatment (which is higher in rural than the urban PHCs). This study also revealed that women in the rural areas had malaria than those in the urban areas, and in treatment of malaria, more women in the rural area than women in the urban areas treat malaria based on doctor's advice while other treatment advice was from using past experience and following friends and families' advice. Hence, the practice of malaria treatment among the respondents of this current study is high and their use of drugs was based on doctors' advice and followed adequate steps towards the treatment of malaria.

\section{REFERENCES}

Awuah, R.B., Asante, P.Y., Sakyi, L. Adriana A. E, Mawuli K. K, Francis A, de-Graft Aikins A. (2018). Factors associated with treatment-seeking for malaria in urban poor communities in Accra, Ghana. Malar J 17, 168. https://doi.org/10.1186/s12936-0182311-8

Fana, S.A., Bunza, M.D.A., Anka, S.A. Imam, A. U, Nataala, S.U. Prevalence and risk factors associated with malaria infection among pregnant women in a semi-urban community of north-western Nigeria. Infect Dis Poverty 4, 24 (2015). https://doi.org/10.1186/s40249-015-0054-0 
Oladimeji O., Okorie N.P., and Adeyeba A.O. (2019): Prevalence and associated factors of Plasmodium falciparum and soil transmitted helminth infections among pregnant women in Osun state, Nigeria. Afr Health Sci.; 18(3): 542-551. doi: 10.4314/ahs.v18i3.11

Rogerson J.S. (2017): (IPTP)Management of malaria in pregnancy. Indian J Med Res; 146(3): 328-333. doi: 10.4103/ijmr.IJMR_1304_17

Saba N., Sultana,.A., Mahsud .I. (2008): Outcome and complications of malaria in pregnancy. Gomal J. Med. Sci; 6, 98-101.

World Health Organization (2020): More pregnant women and children protected from malaria, but accelerated efforts and funding needed to reinvigorate global response. [Online] Available at: https://www.who.int/news/item/04-12-2019-more-pregnantwomen-and-children-protected-from-malaria-but-accelerated-efforts-and-fundingneeded-to-reinvigorate-global-response-who-report-shows (Accessed March 8 2021)

World Health Organization.WHO (2004): Brazzaville: WHO Regional Office for Africa. A strategic framework for malaria prevention and control during pregnancy in the African region. 